\title{
Theoretical insights on the effect of reactive gas on the chemical ordering of gold-based alloys
}

\author{
Hazar Guesmi
}

Published online: 17 September 2013

(C) The Author(s) 2013. This article is published with open access at SpringerLink.com

\begin{abstract}
Alloy catalysts typically operate under highpressure and high-temperature conditions, and these reactive environments may substantially influence the alloy surface composition. Theoretical studies of catalytic properties are often investigated on model systems where no account is taken for the possibility that the surface composition can be modified after the gas exposure. This is a serious drawback that may prevent reliable description of the catalyst reactivity that mainly depends on the configuration of the surface. Nowadays, modelling the equilibrium structure of metal surfaces and alloys in a reactive environment is still a barely studied subject and remains an extremely challenging task. Recent methodological advances and their applications, mainly on gold-based alloy systems, are presented and discussed in this brief overview.
\end{abstract}

Keywords Gold · Alloy · Under gas · Structure · Reactivity

\section{Introduction}

The desire to synthesise efficient catalysts with well-defined, controllable properties and structures at the nanometre scale has generated great interest in bimetallic nanoclusters [1, 2]. One of the major reasons for such interest is the fact that their chemical and physical properties may be tuned by varying the

H. Guesmi

CNRS - Laboratoire de Réactivité de Surface, Université Pierre et

Marie Curie (UMR 7197), 3 rue Galilée, 94200 Ivry, France

H. Guesmi $(\bowtie)$

CNRS - Institut Charles Gerhardt-équipe MACS, Ecole Nationale de Chimie de Montpellier (UMR 5253), 8 rue de l'Ecole Normale, 34296 Montpellier, France

e-mail: hazar.guesmi@enscm.fr composition and the size of the clusters, which leads to different atomic ordering.

Gold-based nanoalloys (or gold alloy nanoparticles) are attracting growing attention due to their specific properties as optical [3], catalytic [2] and electro-catalytic [4] materials. In heterogeneous catalysis, bimetallic gold nanoparticles have shown high reactivity in a number of catalytic reactions including the direct synthesis of hydrogen peroxide from $\mathrm{H}_{2}$ and $\mathrm{O}_{2}[5,6]$, synthesis of vinyl acetate [7], selective hydrogenation of butadiene [8] and so forth. In the context of $\mathrm{CO}$ reforming, recent experiments on gold nanoparticles with different $\mathrm{Ni}$ contents show an improvement of the $\mathrm{CO}$ oxidation rate [9]. Palladium [10] and platinum [11] also emerge as good candidates for the enhancement of such reaction.

Surface structures, compositions and segregation properties of nanoalloys are of prior interest as they are important in determining chemical reactivity and especially catalytic activity. Moreover, the adsorbate-induced segregation of metal alloys under the reaction conditions and thus the changes in local atomic composition and surface structure have been predicted and demonstrated to occur for a number of gold alloy systems $[12,13]$. In particular, for $\mathrm{Au}-\mathrm{Pd}$ nanoalloys (that will be more detailed bellow) although the gold surface enrichment is predicted to be thermodynamically favourable under vacuum conditions [14], a reversed segregation of $\mathrm{Pd}$ as a more active component to the surface is reported to occur in the presence of adsorbates [15-17]. Concerning the adsorbateinduced surface reconstruction, Yoshida et al. [18] have recently reported the results of visualizing gas molecules interacting with supported nanoparticle catalysts at reaction conditions. Using the newly developed aberration-corrected environmental transmission electron microscopy, these authors succeeded to show how adsorbed CO causes the (100) facets of gold nanoparticles to reconstruct into $\mathrm{Au}(100)$-hex. This phenomenon which could also happen on specific gold- 
based alloy systems was not yet visualised. Therefore, while a given local surface structure and ensemble may exhibit a desired property under idealized ultrahigh vacuum conditions, it is important to understand whether the particular configuration is stable under the operating environment for a specific application.

Many theoretical methods are recognized as successful tools to study the structure and the chemical ordering of bulk and surface alloys [19, 20]. For nanoalloys [see 21 and references herein], structural searches via empirical potentials [22, 23], tight-binding [24, 25] and methods based on density functional theory (DFT) calculations $[26,27]$ have been performed. DFT methods, even limited to small bimetallic clusters [28], can be of sufficiently high accuracy, affording the possibility of treating a wide variety of structures and chemical compositions. For instance, by using a quick screen of a large number of bimetallic configurations, DFT methods are able to computationally identify the most stable structure and sometimes to design new catalysts with improved performance [29]. Nevertheless, in the vast majority of theoretical studies, no account is taken for the possibility that the surface composition can be modified during the gas exposure, i.e. in the presence of the adsorbate. In this context, much effort is needed to identify, on one hand, realistic systems in which the structure and chemical order correspond to equilibrium phases (potential energy surface under vacuum) and, on the other hand, the evolution of such phases in the presence of the adsorbates. Up to now, little is known on the latter topic in which many important questions are still open. Therefore, it is important to bring the attention of interested researches and specialists in the field. This paper aims to provide a brief overview of the state of the art of the few theoretical studies devoted to the change occurring on the outermost surface layers of gold-based alloy catalysts during reaction conditions (in situ).

\section{Theoretical approaches}

Two well-established DFT-based methodologies have been employed to model the equilibrium structures of alloys in a reactive environment: the DFT atomistic thermodynamics and the cluster expansion approaches. In addition, DFT vibrational frequency calculations of a probe molecule can help to identify the local atomic surface structure of alloys under reactive gas. This latter characterization method can be useful when combined with experimental results. In general, the interplay between in situ techniques and theory is the better way to bridge the pressure gap [30] and to allow extending the comprehension of the surface state of metallic nanoparticles under reaction conditions. This is of particular importance in the case of multi-metallic catalysts for which reactant-driven changes of the surface composition may occur.

\section{DFT atomistic thermodynamics}

In the early 1970s, DFT methods were firstly employed in simulations of surface phonon. Thanks to the fast increase in computer technology, these simple beginnings developed rapidly into more sophisticate modelling that are able to calculate the geometry of molecular and extended systems to experimental accuracy and bond energies to within a few percent errors [31]. To model extended systems representing alloy surfaces in reactive gas, periodic boundary conditions through a supercell approach are commonly used. By considering the alloy surface in contact with a bulk phase and with the gasphase atmosphere, the free energies of several structures and alloy compositions are calculated to determine the most stable one under specific conditions of temperature and partial pressure of gas-phase species.

Nevertheless, the weakness of this approach is that only ordered alloy structures can be simulated. Furthermore, as small unit cells periodically repeated in space cannot accommodate large deformations that might be induced by the addition of impurities, size mismatch and stresses cannot be considered. Detailed description of the basic features of this approach can be found in [32] for the case of bimetallic alloy in thermodynamic equilibrium with single gas molecule and in $[33,34]$ for the case of multiple gas species.

\section{Cluster expansion method (or lattice-gas-Hamiltonian)}

Cluster expansion (CE) method is a formalism that uses a set of DFT calculations of large number of ordered and disordered fixed structures to extract many-body interaction terms that describe the Hamiltonian of the alloy system [32]. A CE of the Hamiltonian is then termed by a polynomial equation involving the neighbouring energy interactions that, in principle, includes an infinite number of terms and summations. The success of this approach is built upon the fact that, in metal alloys, the strongest interactions are usually short ranged and, therefore, the CE can be truncated. Once the CE is constructed, Monte Carlo simulations at finite temperatures can be performed to study ordered and disordered alloy systems.

In principle, one only needs a finite number of cluster interactions to correctly reproduce the configuration energies. However, this method is limited to the treatments of structures with pre-determined lattice topology.

DFT alloy surface probe

The other way to identify the local atomic surface structure of alloys under reactive gas is to use a probe molecule as $\mathrm{CO}$ for 


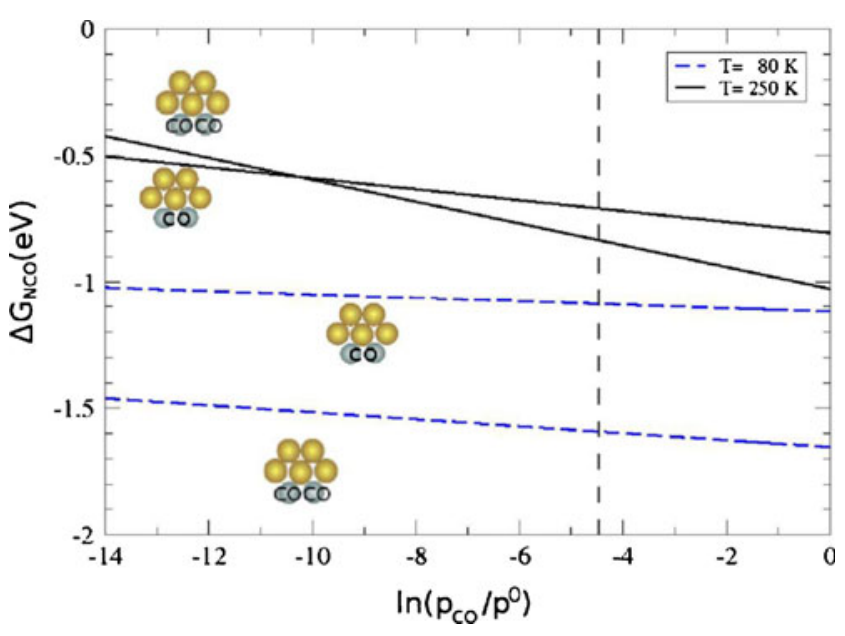

Fig. 1 The excess free energy of single and multiple $\mathrm{CO}$ adsorptions on Pd2@Au dimers, as a function of the pressure. At low temperature, the equilibrium configuration for $\mathrm{CO}$ adsorption on $\mathrm{Pd} 2 @ \mathrm{Au}$ is $2 * \mathrm{CO}$ molecules over all range of pressures, while at high temperature, a single $\mathrm{CO}$ bound to the bridge site is favoured at low pressures and $\mathrm{CO}$ pairs are likely only at high $\mathrm{CO}$ pressures. The crossing between multiple and single $\mathrm{CO}$ adsorption is observed at $p \mathrm{CO} \sim 0.03$ Torr. Reproduced with the permission from [44]

example. The approach is based on the statement that IR bands of carbonyl adsorbed species recorded after $\mathrm{CO}$ introduction are relevant of specific $\mathrm{CO} /$ metal interactions and serve as a fingerprint of the adsorption site $[35,36]$ as well as the surface chemical bonds [37]. Combined with experimental work, DFT energy and harmonic vibrational calculations allow the assignment of spectra, recorded by in situ or operando techniques, thus providing a more reliable description of surface active sites and the nearest chemical environment.

\section{Gold-based alloy systems}

Despite a considerable progress of the application of the previously described DFT methodologies in the identification of equilibrium alloy structures under reactive gas conditions [see the recent reviews 32,38], only very few studies at this level of theory have considered Au-based bimetallic nanosystems. In the following, we briefly review the main theoretical insights in this topic by presenting some examples of gold-based alloy systems.

Bimetallic gold-palladium alloy

$\mathrm{Au}-\mathrm{Pd}$ catalyst is one of the bimetallic systems that have attracted the most significant interest due to its superior performance in various catalytic reactions $[1,2,5-7,10]$. The interplay between gold and palladium components leads to its superior catalytic reactivity in terms of the so-called ligand and ensemble effects [39]. In addition, the evolution of surface composition during exposure to reaction atmosphere seems to enhance, in many cases, the catalytic properties of the $\mathrm{Au}-\mathrm{Pd}$ alloy. For instance, Piccolo et al. have reported that the increase in the conversion rate of hydrogenation of butadiene into butenes observed on $\mathrm{Au}-\mathrm{Pd}$ surfaces during time on stream could partly originate from a modification of the surface composition and precisely from Pd surface enrichment induced by reactant or product adsorption [40]. Recent studies of Goodman's group showed that $\mathrm{CO}$ adsorption induces $\mathrm{Pd}$ segregation on $\mathrm{AuPd}(100)$ surfaces [10,41]. The authors have reported that such segregation leads to the formation of contiguous Pd sites, at least Pd dimers able to dissociate $\mathrm{O}_{2}$, responsible for the observed enhancement of low-temperature $\mathrm{CO}$ oxidation reaction. Moreover, the segregation of $\mathrm{Pd}$ in $\mathrm{Au}-\mathrm{Pd}$ nanoparticles after other gas exposure such $\mathrm{O}_{2}[16]$, $\mathrm{H}_{2}$ [42] and $\mathrm{NO}$ [43] was also observed through various techniques.

From this unique behaviour of $P d$ under reaction conditions, several questions rise: what is the distribution of $P d$ atoms between the surface and bulk phases, and how this distribution depends on CO gas phase, on the temperature and on the Pd concentration?

According to the work of García and López using a first principle-based thermodynamic model, $\mathrm{CO}$-induced segregation
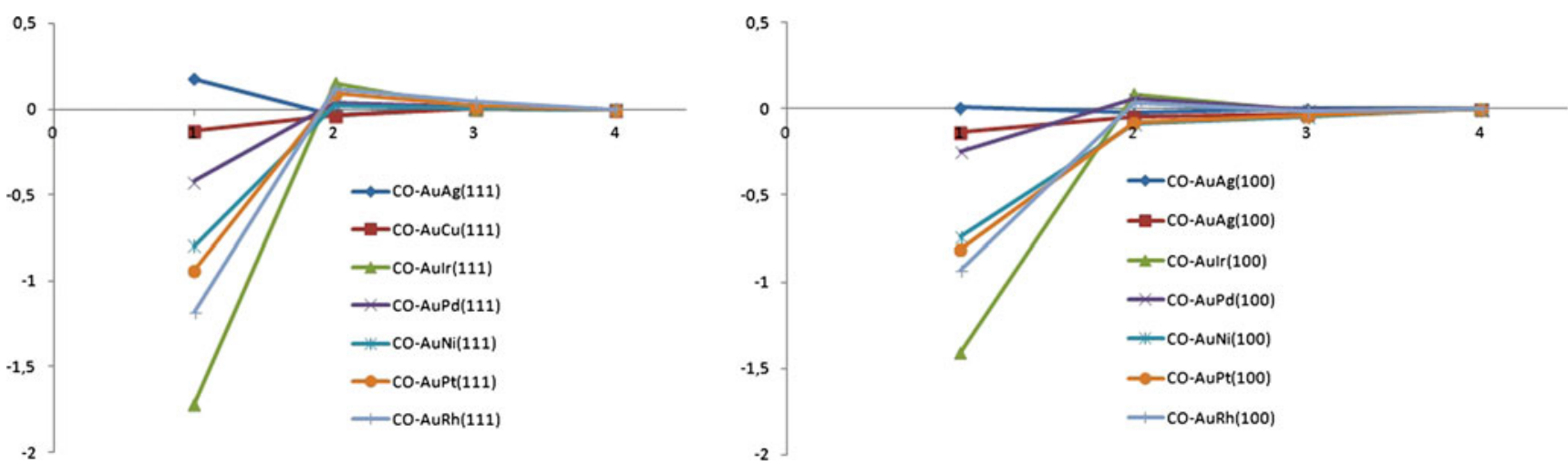

Fig. 2 DFT segregation energies of group 9-10-11 transition metals (TM=Ag, Cu, Ir, Pd, Ni, Pt and Rh), substituted in semi-infinite gold (111) and (100) surfaces, calculated in the presence of $\mathrm{CO}$ 
Fig. 3 Assignations of DRIFT spectra in the carbonyl region of $\mathrm{Au}-\mathrm{Pd}(20) / \mathrm{Al}_{2} \mathrm{O}_{3}$ exposed to $\mathrm{CO}$ to the corresponding DFT calculated local geometries

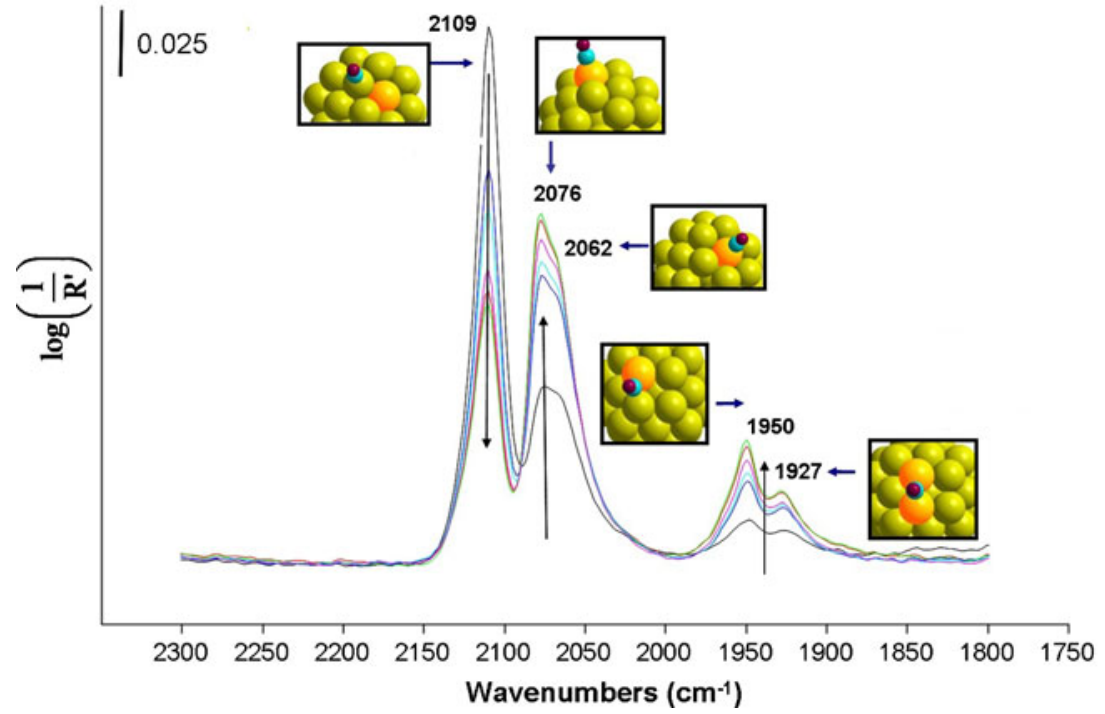

occurs for $\mathrm{PdAu}(111)$ at moderate $\mathrm{CO}$ pressures, about $10^{-2}$ Torr (Fig. 1) [44]. By performing DFT energy calculations coupled by thermodynamics together with a simple lattice-gas model, Soto-Verdugo and Metiu [45] have investigated the equilibrium composition of the (111) and (100) diluted $\mathrm{Au}-\mathrm{Pd}$ alloy exposed to $\mathrm{CO}$ as a function of temperature, $\mathrm{CO}$ pressure and $\mathrm{Pd} / \mathrm{Au}$ ratio. These authors have reported that in the presence of $\mathrm{CO}$, the interaction between two Pd remains less favourable than Au-Pd interaction, which explains the nonformation of aggregates within the surface layer and the nonexistence of Pd domains in the bulk. From the study of equilibrium composition at the surface of spherical nanoalloys, these authors have suggested that the ability of Pd to segregate to the surface was controlled by the binding energy of the reactants to the Pd surface atom. Following the same idea, using DFT periodic calculations in the presence of adsorbed $\mathrm{CO}$, we have recently investigated the segregation behaviours of group 9-1011 transition metals ( $\mathrm{TM}=\mathrm{Ag}, \mathrm{Cu}, \mathrm{Ir}, \mathrm{Pd}, \mathrm{Ni}, \mathrm{Pt}$ and $\mathrm{Rh}$ ), substituted in semi-infinite gold surfaces (Dhouib et al., submitted). The ability of TMs to segregate from the gold bulk to the surface was found to increase by increasing their binding strengths with adsorbed molecule. In addition, the investigation of different surface orientations shows a better segregation of TMs to the closed-packed (111) surface compared to the (100) (Fig. 2). Concerning Au-Pd alloy, we have also shown that the segregation behaviour of $\mathrm{Pd}$ was oxygen coverage-dependent
Fig. 4 DFT calculated formation energies of $\mathrm{Au}-\mathrm{Pt}$ surface alloys on $\mathrm{Pt}(111)$. The grey lines connecting the lowest energy structures show a convex hull, indicating ordered structures exist for the surface. Red dots are striped structures with the size of the circles showing the average period of the stripes. The black line shows the formation energies of the random surfaces, and the green square is the formation energy of the 2D special quasirandom structure generated at $50 \%$ composition. Reproduced with permission from [52]

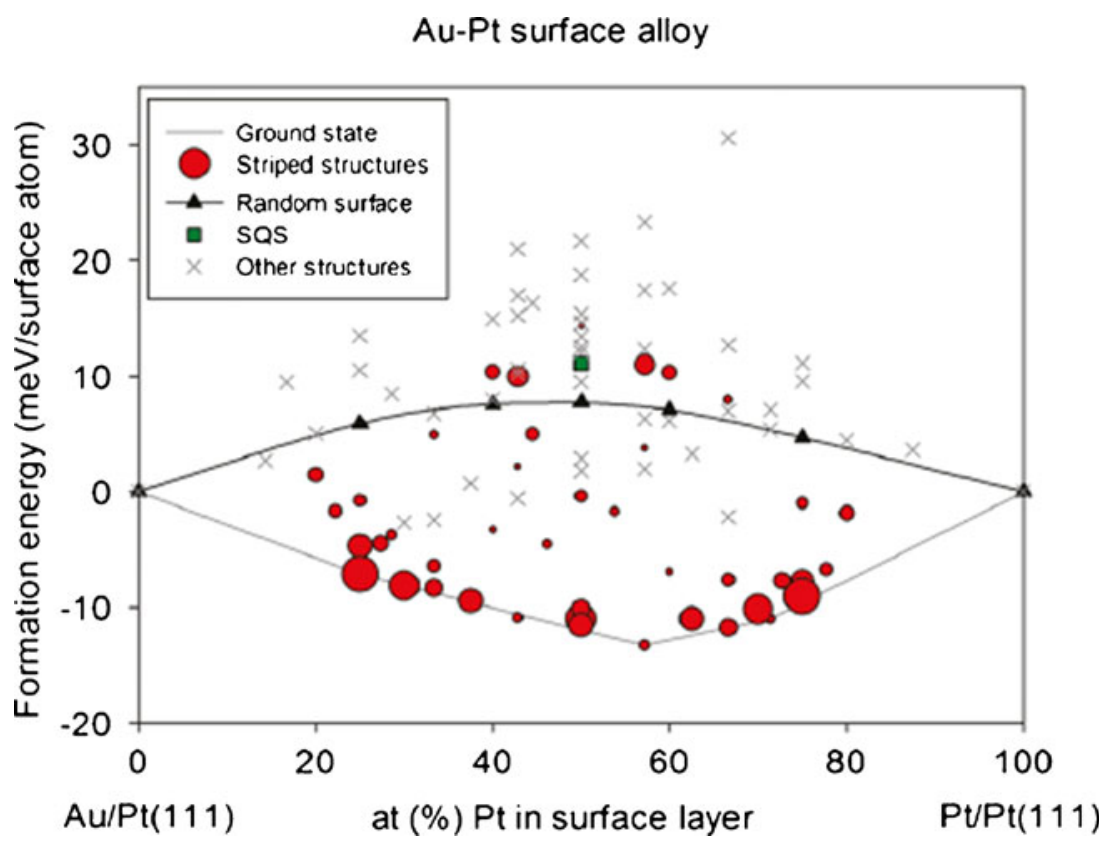


[15]. Indeed, the DFT energy calculations predict that at $T=0 \mathrm{~K}$, Pd segregation to the surface occurs only in the presence of more than $1 / 3 \mathrm{ML}$ of chemisorbed oxygen. This is not the case for $\mathrm{Au}-\mathrm{Pt}$ and $\mathrm{Au}-\mathrm{Ni}$ alloys where, as soon as one oxygen atom is adsorbed, the stability of the metal impurities is reversed from the bulk to the surface [16]. Both $\mathrm{CO}$ and $\mathrm{H}$ chemisorption effects on the chemical ordering of bimetallic $\mathrm{Au}-\mathrm{Pd}$ clusters have been reported by West et al. [46]. From calculated DFT ligand bonding strengths, these authors have predicted that in contrast with conditions under $\mathrm{CO}$ atmosphere, core-shell segregation inversion under $\mathrm{H}_{2}$ could not be favourable.

In a recent work devoted to the calculation of $\mathrm{CO}-\mathrm{Pd}$ frequencies and IR experimental assignments, we have demonstrated that in gold-palladium nanoalloys (with very low Pd loading), only isolated or dimer palladium could exist on the surface [17]. This combined approach allowed identification of different $\mathrm{CO}$ alloy-bonding and quantification of all $\mathrm{Pd}-$ type coordinations of the surface in the presence of gas (Fig. 3). Moreover, from energetic and electronic analysis, the DFT results have shown that, under conditions where migration and restructuring can occur, $\mathrm{Pd}$ would migrate towards the edge positions on small AuPd nanoparticles.

Finally, for designing new bimetallic catalysts for specific applications, several DFT calculations were devoted to the prediction and to the comparison of the free activation energies of bond breakings and bond formations of intermediates during reaction conditions. For instance, by comparing the dissociation energy barriers of $\mathrm{NO}$ on a series of doped gold surfaces, Fajín et al. [47] have recently demonstrated that NO dissociation is only possible in the case of the $\operatorname{Ir}-\mathrm{Au}(110)$ bimetallic surface but only at high temperature. In a similar context, by investigating the effect of surface structure on the catalytic activity of Au-Pd alloy, Wei et al. [48] have demonstrated by means of DFT reaction energy profile calculations that alloying Pd with gold would facilitate the desorption of $\mathrm{O}_{2}$, which is generally the rate-determining step for $\mathrm{N}_{2} \mathrm{O}$ decomposition reaction.

\section{Bimetallic gold-platinum alloy}

Alloying of Pt catalysts has been found to improve activity and selectivity as compared to the respective monomeric system. For example, a $\mathrm{Cu}-\mathrm{Pt}$ surface alloy shows better activity than $\mathrm{Pt}$ for the water-gas shift reaction because the surface alloy better activates $\mathrm{H}_{2} \mathrm{O}$ and at the same time binds $\mathrm{CO}$ more weakly [49]. A Pt monolayer on $\operatorname{Pd}(111)$ has improved activity for the oxygen reduction reaction as compared to a pure $\mathrm{Pt}$ catalyst [50]. Similarly to the Au-Pd system, Pt-based alloy system can show surface modifications and segregation in the presence of reactive gas. Using density functional theory, Tenney et al. have shown that it is thermodynamically more favourable for $\mathrm{Pt}$ to diffuse to the $\mathrm{Au}-\mathrm{Pt}$ cluster surface in order to bind to CO [51]. By using CE-based DFT method, Chen and co-workers [52] have studied the surface structure and ordering of a mixed $\mathrm{Au}-\mathrm{Pt} / \mathrm{Pt}(111)$ surface alloy and have investigated the related oxygen binding. The DFT energies of about $90 \mathrm{Au}-$ Pt structures were used as input to train the surface CE Hamiltonian. Even though the Au-Pt system is well known to phase separate in the bulk (miscibility gap), this alloy showed a series of stable low-temperature lateral ordered striped structures (Fig. 4). The existence of such structures was explained by the competition between the energy penalty of $\mathrm{Au}-\mathrm{Pt}$ bonds at the boundaries between the stripes and the favourable strain relaxation from forming stripes. Because the presence of adsorbates can alter the atomic ordering of the surface atoms, these latter authors have investigated the effect of adsorbed oxygen on these ordered and disordered identified $\mathrm{Au}-\mathrm{Pt}$ structures. The calculation of molecular oxygen binding was found to be highly correlated with the type of local surface alloy arrangement but information concerning structure change after such oxygen adsorption remains missing.

\section{Conclusions}

In the presence of adsorbates, the surface composition may change due to the adsorbate effect on solute segregation tendencies. The understanding of surface segregation is thus of primary importance for controlling the behaviour of bimetallic catalysts. However, due to the complexity of the alloy systems, segregation and surface structure are often difficult to predict. By the consequence, in spite of the considerable progress of the theoretical methodologies for the identification of bulk and surface alloy structures under idealized ultrahigh vacuum conditions, very few studies are devoted to the equilibrium alloy structures under reactive gas conditions. In this paper, the recent slight progresses in this challenging task were briefly reviewed through some gold-based alloy examples.

Acknowledgment The author acknowledges the support of EU (COST-MP0903) and addresses her warm thanks to Dr. Tzonka Minèva for the critical reading of the manuscript.

Open Access This article is distributed under the terms of the Creative Commons Attribution License which permits any use, distribution, and reproduction in any medium, provided the original author(s) and the source are credited.

\section{References}

1. Hugon A, Delannoy L, Krafft J-M, Louis C (2010) Supported goldpalladium catalysts for selective hydrogenation of 1,3 butadiene in an excess of propene. J Phys Chem C 114:10823-10835

2. El Kolli N, Delannoy L, Louis C (2013) Bimetallic Au-Pd catalysts for selective hydrogenation of butadiene: influence of the preparation method on catalytic properties. J Cat 297:79-92 
3. Alissawi N, Zaporojtchenko V, Strunskus T, Kocabas I, Chakravadhanula VSK, Kienle L, Garbe-Schönberg D, Faupel F (2012) Effect of gold alloying on stability of silver nanoparticles and control of silver ion release from vapor-deposited $\mathrm{Ag}-\mathrm{Au} /$ polytetrafluorethylene nanocomposites. Gold Bull 46:3-11

4. Luo J, Wang LY, Mott D, Njoki P, Lin Y, He T, Xu Z, Wanjana B, IIm Lim S, Zhong CJ (2008) Core@Shell nanoparticles as electrocatalysts for fuel cell reactions. Adv Mater 20:4342-4347

5. Edwards JK, Hutchings GJ (2008) Palladium and gold-palladium catalysts for the direct synthesis of hydrogen peroxide. Angew Chem Int Ed 47:9192-9198

6. Edwards JK, Solsona B, Carley AF, Herzing AA, Kiely CJ, Hutchings GJ (2009) Switching-off hydrogen peroxide hydrogenation in the direct synthesis process. Science 323:1037-1041

7. Chen M, Kumar D, Yi CW, Goodman DW (2005) The promotional effect of gold in catalysis by palladium-gold. Science 310 : 291-293

8. Hugon A, El Kolli N, Louis C (2010) Advances in the preparation of supported gold catalysts: mechanism of deposition, simplification of the procedures and relevance of the elimination of chlorine. J Catal 274:239-250

9. Chandler BO, Long CG, Gilberson JD, Pursell CJ, Vijayaraghavan G, Stevenson KJ (2010) Enhanced oxygen activation over supported bimetallic Au-Ni catalysts. J Phys Chem C 114:11498-11508

10. Gao F, Wang Y, Goodman DW (2009) CO oxidation over AuPd(100) from ultrahigh vacuum to near-atmospheric pressures: the critical role of contiguous Pd atoms. J Am Chem Soc 131:5734-5735

11. Zhou S, Jackson GS, Eichhorn B (2007) Architectural effects on the catalytic activity of Au-Pt bimetallic nanostructures: alloys and contact aggregates particles for $\mathrm{CO}$ tolerant hydrogen activation. Adv Funct Mater 17:3099-3104

12. García-Mota M, López N (2011) The role of long-lived oxygen precursors on AuM alloys $(\mathrm{M}=\mathrm{Ni}, \mathrm{Pd}, \mathrm{Pt}, \mathrm{Pt})$ in $\mathrm{CO}$ oxidation. Phys Chem Chem Phys 13:5790-5797

13. Tenney SA, He W, Roberts CC, Ratliff JS, Shah SI, Shafai GS, Turkowski V, Rahman TS, Chen DA (2011) CO-induced diffusion of $\mathrm{Ni}$ atoms to the surface of Ni-Au clusters on TiO2(110). J Phys Chem C 115:11112-11123

14. Pittaway F, Paz-Borbón LO, Johnston RL, Arslan H, Ferrando R, Mottet C, Barcaro G, Fortunelli A (2009) Theoretical studies of palladium-gold nanoclusters: Pd-Au clusters with up to 50 atoms. J Phys Chem C 113:9141-9152

15. Guesmi H, Louis C, Delannoy L (2011) Chemisorbed atomic oxygen inducing Pd segregation in $\operatorname{PdAu}\left(\begin{array}{lll}1 & 1 & 1\end{array}\right)$ alloy: energetic and electronic DFT analysis. Chem Phys Lett 503:97-100

16. Dhouib A, Guesmi H (2012) DFT study of the M segregation on $\mathrm{MAu}$ alloys $(\mathrm{M}=\mathrm{Ni}, \mathrm{Pd}, \mathrm{Pt})$ in presence of adsorbed oxygen $\mathrm{O}$ and O2. Chem Phys Lett 521:98-103

17. Zhu B, Thrimurthu G, Delannoy L, Louis C, Mottet C, Creuze J, Legrand B, Guesmi H (2013) Evidence of Pd segregation and stabilization at edges of AuPd nano-clusters in the presence of $\mathrm{CO}$ : a combined DFT and DRIFTS study. J Catal. doi:10.1016/j.jcat.2013. 08.022

18. Yoshida H, Kuwauchi Y, Jinschek JR, Sun K, Tanaka S, Kohyama M, Shimada S, Haruta M, Takeda S (2012) Visualizing gas molecules interacting with supported nanoparticulate catalysts at reaction conditions. Sience 335:317-319

19. Treglia G, Legrand B (1987) Surface-sandwich segregation in Pt-Ni and Ag-Ni alloys: two different physical origins for the same phenomenon. Phys Rev B 35:4338-4344

20. Treglia G, Legrand B, Maugain P (1990) Surface segregation in CuNi and $\mathrm{AgNi}$ alloys formulated as an area-preserving map. Surf Sci 225: 319-330

21. Ferrando R, Jellinek J, Johnston RL (2008) Nanoalloys: from theory to applications of alloy clusters and nanoparticles. Chem Rev 108: $845-910$
22. Bochicchio D, Ferrando R (2010) Size-dependent transition to highsymmetry chiral structures in $\mathrm{AgCu}, \mathrm{AgCo}, \mathrm{AgNi}$ and $\mathrm{AuNi}$ nanoalloys. Nano Lett 10:4211-4216

23. Bochicchio D, Ferrando R (2013) Morphological instability of coreshell metallic nanoparticles. Phys Rev B 87(16):13

24. Moreno V, Creuze J, Berthier F, Mottet C, Tréglia G, Legrand B (2006) Site segregation in size-mismatched nanoalloys: application to $\mathrm{Cu}-\mathrm{Ag}$. Surf Sci 600:5011-5020

25. Creuze J, Braems I, Berthier F, Mottet C, Tréglia G, Legrand B (2008) Model of surface segregation driving forces and their coupling. Phys Rev B 78:075413

26. Barcaro G, Fortunelly A, Polak M, Rubinovich L (2011) Patchy multishell segregation in Pd-Pt alloy nanoparticles. Nano Lett 11: 1766-1769

27. Rossi G, Rapallo A, Mottet C, Fortunelli A, Baletto F, Ferrando R (2004) Magic poluicosahedral core-shell clusters. Phys Rev Lett 93(10):105503-1055037

28. Heiles S, Logsdail AJ, Sch fer R, Johnston RL (2012) Dopantinduced 2D-3D transition in small Au-containing clusters: DFTglobal optimization of 8-atom Au-Ag nanoalloys. Nanoscale 4: $1109-1115$

29. Norskov JK, Biligaard T, Rossmeisl J, Christensen CH (2009) Towards the computational design of solid catalysts. Nat Chem 1: $37-46$

30. Molenbroek AM, Helveg S, Topsøe H, Clausen BS (2009) Nanoparticles in heterogeneous catalysis. Top Catal 52:1303-1311

31. Tielens F, Calatayud M (2011) The synergistic power of theory and experiment in the field of catalysis Preface. Catal Today 177:1-2

32. Zafeiratos S, Piccinin S, Teschner D (2012) Alloys in catalysis: phase separation and surface segregation phenomena in response to the reactive environment. Catal Sci Tech 2:1787-1801

33. Sun Q, Reuter K, Scheffler M (2003) Effect of a humid environment on the surface structure of $\mathrm{RuO}_{2}(110)$. Phys Rev B: Condens Matter 67:205424-205431

34. Nguyen NL, Piccinin S, de Gironcoli S (2011) Stability of intermediate states for ethylene epoxidation on $\mathrm{Ag}-\mathrm{Cu}$ alloy catalyst: a firstprinciples investigation. J Phys Chem C 115:10073-10079

35. Lamberti C, Bordiga S, Geobaldo F, Zecchina A, Otero Areán C (1995) Stretching frequencies of cation-CO adducts in alkali-metal exchanged zeolites: an elementary electrostatic approach. J Chem Phys 103:3158-3166

36. Cairon O, Guesmi H (2011) How does CO capture process on microporous NaY zeolites? A FTIR and DFT combined study. Phys Chem Chem Phys 13:11430-11437

37. Risse T, Carlsson A, Baumer M, Kluner T, Freund HJ (2003) Using IR intensities as a probe for studying the surface chemical bond. Surf Sci 546:L829-L835

38. Tao F, Zhang S, Nguyen L, Zhang X (2012) Action of bimetallic nanocatalysts under reaction conditions and during catalysis: evolution of chemistry from high vacuum conditions to reaction conditions. Chem Soc Rev 41:7980-7993

39. Boscoboinik JA, Calaza FC, Garvey MT, Tysoe WT (2010) Identification of adsorption ensembles on bimetallic alloys. J Phys Chem C 114:1875-1880

40. Piccolo L, Piednoir A, Bertolini JC (2005) Pd-Au single-crystal surfaces: segregation properties and catalytic activity in the selective hydrogenation of 1,3-butadiene. Surf Sci 592:169-181

41. Gao F, Wang YL, Goodman DW (2009) CO adsorption-induced surface segregation and reaction kinetics. J Phys Chem C 13: 14993-15000

42. Di Vece M, Bals S, Verbeeck J, Lievens P, Van Tendeloo G (2009) Compositional changes of $\mathrm{Pd}-\mathrm{Au}$ bimetallic nanoclusters upon hydrogenation. Phys Rev B 80(12):4

43. de Bocarmé TV, Moors M, Kruse N, Atanasov IS, Hou M, Cerezo A, Smith GDW (2009) Surface segregation of Au-Pd alloys in UHV and 
reactive environments: quantification by a catalytic atom probe. Ultramicroscopy 109:619-624

44. García M, López N (2010) Temperature and pressure effects in CO titration of ensembles in $\mathrm{PdAu}(111)$ alloys using first principles. Phys Rev B 82(7):9

45. Soto-Verdugo V, Metiu H (2007) Segregation at the surface of an $\mathrm{Au} /$ Pd alloy exposed to CO. Surf Sci 601:5332-5339

46. West PS, Johnston RL, Barcaro G, Fortunelli A (2010) The effect of $\mathrm{CO}$ and $\mathrm{H}$ chemisorptions on the chemical ordering of bimetallic clusters. J Phys Chem C 114:19678-19686

47. Fajín JLC, Cordeiro MNDS, Gomes JRB (2013) A DFT study of the NO dissociation on gold surfaces doped with transition metals. J Chem Phys 138:74701-74710

48. Wei X, X-F Yang A-Q, Wang LL, Liu X-Y, Zhang T, Mou C-Y, Li J (2012) Bimetallic Au-Pd alloy catalysts for N2O decomposition: effects of surface structures on catalytic activity. J Phys Chem C 116:6222-6232

49. Nilekar AU, Mavrikakis M (2008) Improved oxygen reduction reactivity of platinum monolayers on transition metal surfaces surf. Sci 602:L89-L94

50. Tenney SA, Ratliff JS, Roberts CC, He W, Ammal SC, Hayden A, Chen DA (2010) Adsorbate-induced changes in the surface composition of bimetallic cluster: Pt-Au on TiO2(110). J Phys Chem C 114: 21652-21663

51. Knudsen J, Nilekar AU, Vang RT, Schnadt J, Kunkes EL, Dumesic JA, Mavrikakis M, Besenbacher F (2007) A Cu/Pt near-surface alloy for water-gas shift catalysis. J Am Chem Soc 129:6485-6490

52. Chen W, Schmidt D, Schneider WF, Wolverton C (2011) Ordering and oxygen adsorption in Au-Pt/Pt(111) surface alloys. J Phys Chem C 115:17915-17924 